\title{
Static and dynamic water wells levels of Kirkuk city represented by geo-statistical algorithms in GIS
}

\author{
Ghadah Mohammed $^{1}$ \\ ${ }^{1}$ Northern Technical University, Kirkuk, Iraq
}

\begin{abstract}
Water is great importance for human life as well as for agriculture therefore, different scientific methods are used for curtailed the time and possibilities for well water sources investigation. Fresh water is the most importance for Human life and cannot be healthy without it. In the paper two different interpolation methods were used, which are the ordinary kriging and Inverse Distance Weighting (IDW) to predict static and dynamic water levels of wells in Kirkuk City, and the number of wells was 64. The data of wells were obtained from digging water wells in Directorate of Kirkuk. By using different methods different results were introduced. Furthermore, three wells were used as testing wells for interpolation algorithms.These are office of the Nation Mission, the Emergency department, and Wahid Athar district wells and it was found that the Emergency department well is the most accurate and nearest from the actual levels for both static and dynamic with RMSE of -2.23 and - 1.35 in kriging method respectively as well as -2.97 and -2.65 respectively in IDW method. However, the average of the three testing wells overall IDW interpolation algorithm is the best, accurate and nearest from the true elevations in stable levels of wells.
\end{abstract}

\section{Introduction}

With the necessary human needs for water, the various scientific methods used to increase saving time and possibilities to search for well water sources. Fresh water considered the most important for human life, as life itself is not possible without it. Also fresh water cannot be substituted by anything else. Fresh water and the various natural surface water bodies had used and consumed by human for a wide range of purposes (1). At the same time, in many Western Asian countries the further extraction of surface and groundwater resources through the subsidization and centralization of large- and small-scale agricultural production result from changing development paradigms and political uncertainties prompted the adoption of national policies to pursue food security through food self-sufficiency (3).

There is an ever-growing demand for information on groundwater hydrology and on the hydraulics of the movement of water in aquifers because groundwater plays an important role in the developing and managing of water resources. (2). Therefore, the search, store and use them, as an alternative is necessary for surface water. The method used wells to extract groundwater from the earth in various depths and the various compounds contained in the water and by the geology of the ground core. Static and dynamic water levels were predicted in this study.

During the few years, the most popular computer program is the Geographic Information System (GIS). By GIS program the data cannot acquire, always updating, as well as we can analyzing and modelling the data by it (5). Many studies by GIS were prepared for processing region and city center. (4) a Hydrogeological study about Adana city settlement by GIS program. Water quality analyze maps prepared and groundwater level maps. Researches were prepared for aquifers and basins of larger areas with the same way.

In this study, static and dynamic water levels of wells in the Kirkuk City were selected, which are 64 wells. The geographical locations of the wells were converted to the UTM coordinates system by using website to convert them online. Then, I corrected the coordinates of some wells locations by our experience about the study area. For prediction the static and dynamic water level of Kirkuk City, the interpolation analyst in GIS with two difference methods were used, which are Kriging and Inverse Distance Weighting (IDW). Furthermore, I compared between the two interpolation methods after testing them by three wells. The main objectives of this study are generating data for wells for areas that unobserved or do not have available wells as well as comparing different geostatistical interpolation methods and choosing the best one close to the.

\section{Material and methods}

In this paper, geo-statistical algorithms ordinary kriging and Inverse Distance Weighting (IDW) used to predict static and dynamic water levels of wells in the selected area (Kirkuk City) which are 64 wells. The data and 
information of wells Kirkuk city obtained from digging water wells Directorate of Kirkuk.

\section{Study area}

Fig. (1) Shows Kirkuk City located in north of Iraq is the capital of the Kirkuk province. A city located at longitude $44^{\circ} 00^{\prime} \mathrm{E}$ to $44^{\circ} 50^{\prime} \mathrm{E}$ and latitude $35^{\circ} 13^{\prime} \mathrm{N}$ to $36^{\circ} 29^{\prime} \mathrm{N}$ with a total area of $96.79 \mathrm{~km} 2$.it is 236 kilometers north of the capital, Baghdad. The average elevation of Kirkuk is 346 meters. Kirkuk is located in a vast area with a very diverse population and dramatic demographic changes in the twentieth century. Kirkuk has multilingual, and the development of distinct ethnic groups was a process that took place throughout the twentieth century of urbanization in Kirkuk.

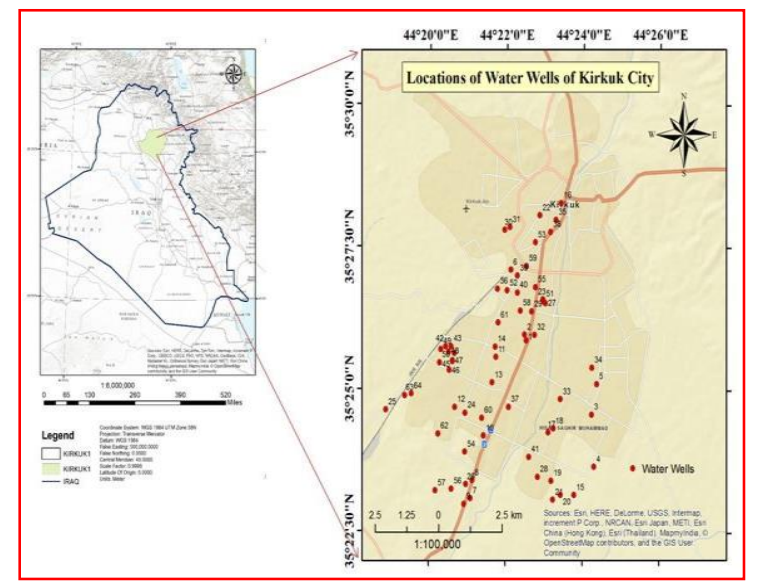

Fig. 1. Location map of study area and observation water wells.

\section{Interpolation methods}

\subsection{Ordinary kriging}

Kriging is a geo-statistical interpolation method, which is the statistical models that include autocorrelation based on statistical models-which is, the statistical relationships among the measured points. That is the reason behind the geo-statistical techniques capable to predict the surface of the production in additional to that it provides a certainty measurements or precise predictions.

Kriging's theory presumably that the direction or distance among sampling points reflects a spatial link which, can be used to illustrates the variation in the surface. This tool commensurate with the mathematical function for some points or all points within a specified radius for determining the output value for each location. Kriging tool are a multi-stage operations. It involves modeling of variables, exploratory statistical analysis of data, (optionally) exploring the surface of variance, as well as creating a surface. Kriging is the best tool when there is directional bias in the data or a spatially connected distance. They often used in geology and soil science (6).

\section{$\mathrm{Z}\left(\mathrm{S}_{\mathrm{i}}\right)$}

$$
\widetilde{Z}\left(s_{0}\right)=\sum_{i=1}^{N} \lambda_{i} Z\left(s_{i}\right)
$$

Where:

$=$ the value measured at

the ith location

$\lambda \mathrm{i}=$ an unknown weight for the value measured at the ith location

$\mathrm{S}_{0}=$ forecast site

$\mathrm{N}=$ the number of values measured

\subsection{Inverse Distance Weighted (IDW)}

Inverse Distance Weighted is the simplest, most readily, and one of the most precise techniques of interpolation. The assumption behind IDW is that the value of nonsampled points can estimated as a weighted average of values at sampled surrounding points As much; the surrounding sampled points are near to the non-sampled point, as the value accuracy of the point increases (7).

$$
Z_{0}=\frac{\sum_{i=1}^{N} Z_{1} d_{1}^{-n}}{\sum_{i=1}^{N} d_{1}^{-n}}
$$

$\mathrm{Z}_{\mathrm{o}}=$ the estimation value of variable $\mathrm{z}$ in point $\mathrm{i}$.

$\mathrm{Z}_{\mathrm{i}}=$ sample value in point $\mathrm{i}$.

$\mathrm{d}_{1}=$ distance between sample point and estimated point.

$\mathrm{N}=$ A coefficient that determines weigh based on a distance.

\section{Results and discussion}

\subsection{Interpolation results}

\subsubsection{IDW interpolation of static elevation}

Fig. (2) Shows the IDW interpolation method for elevation map of Kirkuk City wells. We can classify the stable elevations in to four main classes, which are very high, high, moderate, and low. The first class is starting from $256.2079322 \mathrm{~cm}$ to $268.1243654 \mathrm{~cm}$, from $268.1243655 \mathrm{~cm}$ to $294.9363403 \mathrm{~cm}$, which represents the highest stable elevation represented by white and light purple colors, and distributes in the north part of study area. The second class is starting from $219.8628107 \mathrm{~cm}$ to $240.7165688 \mathrm{~cm}$ and from $240.7165689 \mathrm{~cm}$ to $256.2079321 \mathrm{~cm}$ illustrates the high class, which is the 
dark purple and dark brown colors and distributes in the center, east, and west parts of study.

Fig.2. IDW interpolation of Stable elevation map for

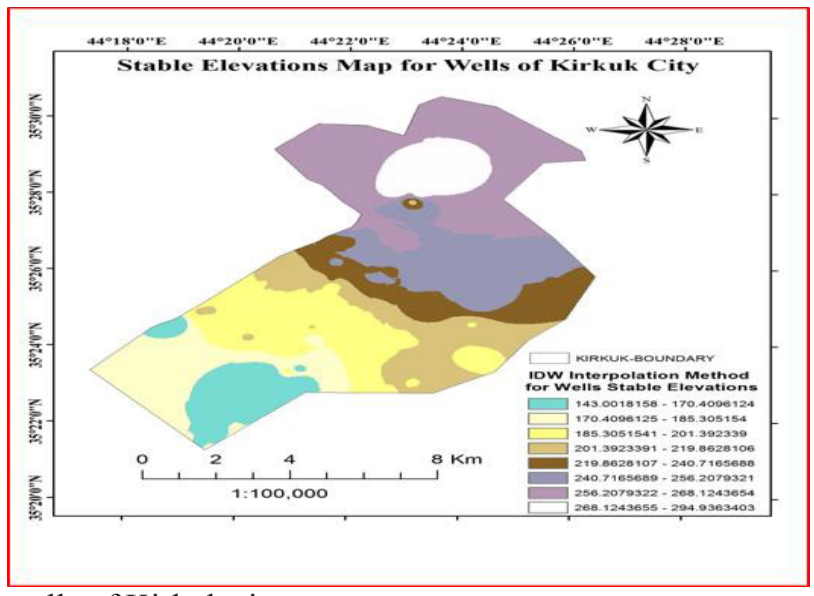

wells of Kirkuk city.

area. The third class is starting from $185.3051541 \mathrm{~cm}$ to $201.392339 \mathrm{~cm}$, from $201.3923391 \mathrm{~cm}$ to 219.8628106 $\mathrm{cm}$, illustrates the moderate class represented by light brown and light yellow colors, and distributes in the center, and eastern and western south parts of study area.

The fourth class is starting from $143.0018158 \mathrm{~cm}$ to $170.4096124 \mathrm{~cm}$, from $170.4096125 \mathrm{~cm}$ to 185.3051514 $\mathrm{cm}$ and the low class represented by celestial and offwhite colors, and distributes in the south and western south parts of the study area map.

\subsubsection{IDW interpolation of Dynamic elevation}

Fig. (3) shows the IDW interpolation method for dynamic elevation map of Kirkuk City wells. We can classify the stable elevations in to four main classes, which are very high, high, moderate, and low. The first class is starting from $273.3054678 \mathrm{~cm}$ to $287.2524524 \mathrm{~cm}$, from $287.2524525 \mathrm{~cm}$ to $311.927887 \mathrm{~cm}$ illustrates most high stable elevation represented by orange and dark red colors, and distributes in the north part of study area. The second class is starting from $243.8022308 \mathrm{~cm}$ to $258.8220604 \mathrm{~cm}$ and from $258.8220605 \mathrm{~cm}$ to $273.3054677 \mathrm{~cm}$ illustrates the high class, which is the yellow and green colors and distributes in the center, east, and west parts of study area. The third class is starting from $209.4711914 \mathrm{~cm}$ to $225.5638661 \mathrm{~cm}$ and from $225.5638662 \mathrm{~cm}$ to $243.8022307 \mathrm{~cm}$, clears the moderate class represented by dark blue and celestial colors, and distributes in the center and eastern and western south parts of study area. The fourth class is starting from $175.140152 \mathrm{~cm}$ to $198.7427415 \mathrm{~cm}$ and from $198.7427416 \mathrm{~cm}$ to $209.4711913 \mathrm{~cm}$ and clears the low class represented by pink and white colors and distributes in the south, eastern and western south parts of the study area map.

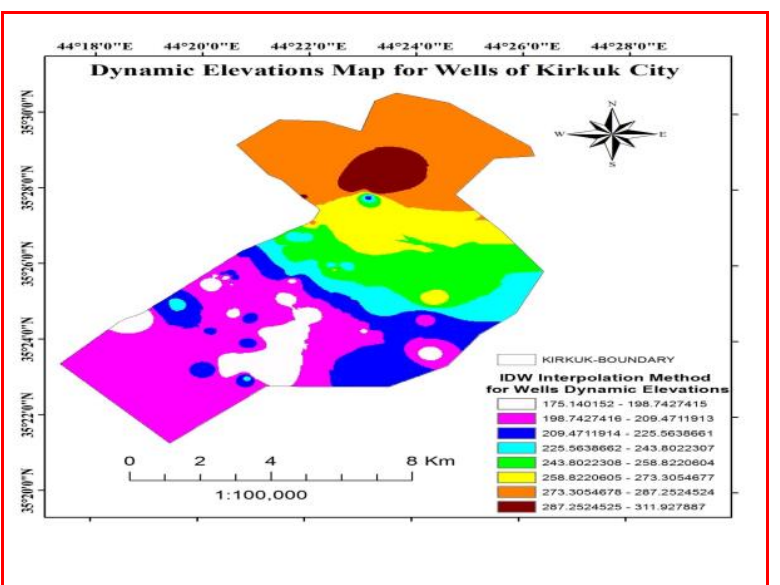

Fig. 3. IDW interpolation of dynamic elevation map for wells of Kirkuk city.

\subsubsection{Kriging interpolation of Stable elevation}

Fig. (4) states the kriging interpolation method for Stable elevation map of Kirkuk City wells. The stable elevations can be classified in to four main classes, which are very high, high, moderate, and low. The first class is starting from $267.7103578 \mathrm{~cm}$ to $286.4908393 \mathrm{~cm}$, from $286.4908394 \mathrm{~cm}$ to $299.6371765 \mathrm{~cm}$ illustrates most high stable elevation represented by red and dark orange colors, and distributes in the north part of study area. The second class is starting from $227.0193141 \mathrm{~cm}$ to $247.0518278 \mathrm{~cm}$ and from $247.0518279 \mathrm{~cm}$ to $267.7103577 \mathrm{~cm}$ illustrates the high class, which is the light orange and yellow colors and distributes in the center, east, and west parts of study area. The third class is starting from $184.4502223 \mathrm{~cm}$ to $205.1087521 \mathrm{~cm}$ and from $205.1087522 \mathrm{~cm}$ to $227.019314 \mathrm{~cm}$, clears the moderate class represented by light yellow and light green colors, and distributes in the center and eastern and western south parts of study area. The fourth class is starting from $140.00308823 \mathrm{~cm}$ to $160.6616121 \mathrm{~cm}$ and from $160.6616122 \mathrm{~cm}$ to $184.4502222 \mathrm{~cm}$ and shows, the low class represented by light green and dark green colors and distributes in the south part of the study area map.

\subsubsection{Kriging interpolation of Dynamic elevation}

States the kriging interpolation method for Dynamic elevation map of Kirkuk City wells. We can classify the elevations in to four main classes, which are very high, high, moderate, and low. The first class is starting from $283.7948575 \mathrm{~cm}$ to $304.3256078 \mathrm{~cm}$, from 304.3256079 $\mathrm{cm}$ to $316.5330811 \mathrm{~cm}$ illustrates most high stable elevation represented by dark red and dark orange colors, and distributes in the north part of study area. The second class is starting from $246.0626676 \mathrm{~cm}$ to 262.1543368 $\mathrm{cm}$ and from $262.1543368 \mathrm{~cm}$ to 283.7948574 illustrates 
the high class, which is the light orang and desert colors and distributes in the center, east, and west parts of study area. The third class is starting from $212.2146737 \mathrm{~cm}$ to $228.3063428 \mathrm{~cm}$, from $228.3063429 \mathrm{~cm}$ to 246.0626675 $\mathrm{cm}$, clears the moderate class represented by grey and light grey colors, and distributes in the center, and eastern and western south parts of study area. Fig. (5) illustrate the fourth class is starting from $175.0373688 \mathrm{~cm}$ to $198.3425449 \mathrm{~cm}$ and from $198.342545 \mathrm{~cm}$ to $212.2146736 \mathrm{~cm}$ and clears, the low class represented by light and dark blue colors and distributes in the south, eastern and western south parts of the study area map.

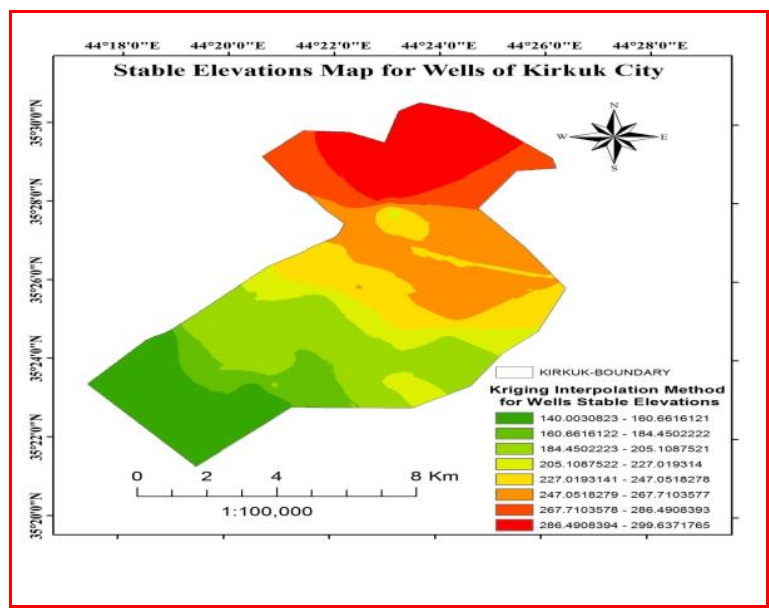

Fig. 4. Kriging interpolation of Stable elevation map for wells of Kirkuk city.

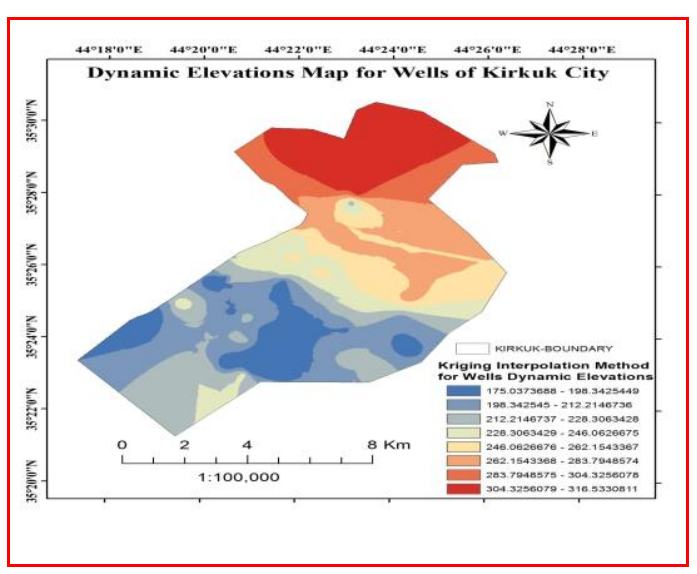

Fig. 5. Kriging interpolation of Dynamic elevation map for wells of Kirkuk city.

\subsection{Validation}

Three wells used to test the interpolation methods, which are Office of the United Nations Mission well, the emergency department well, and Wahid Athar district well. The testing wells distributed on study area by homogeneous form. After that, the testing wells checked with the interpolation predict information to examine the validation of each methods i.e. ordinary kriging and IDW methods. The results of testing are illustrated in Table 1 \& 2, as follows: in kriging method, the Emergency department well was the most accurate and nearest from the actual levels, where the difference in level between the testing and interpolation result for both static and dynamic with $-2.23 \mathrm{~cm}$ and $-1.35 \mathrm{~cm}$, respectively. Likewise the same testing well which is the Emergency department got accurate and closer results from IDW interpolation method, where $2.97 \mathrm{~cm}$ and $-2.65 \mathrm{~cm}$ for static and dynamic respectively. And so on, the average difference level of the three testing wells overall IDW interpolation algorithm is the best, accurate and closer from the true elevations in stable levels of wells.

Table 1. Validation in levels between Testing wells water level and Ordinary Kriging Method.

\begin{tabular}{|c|c|c|c|c|c|c|c|}
\hline ID & 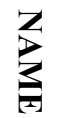 & $\mathscr{\Omega}$ & $\underline{\theta}$ & $\frac{\Omega}{\lambda}$ & $\underset{\pi}{\bar{\pi}}$ & $\underset{\mathscr{Q}}{\mathscr{Q}}$ & $\underset{\theta}{\theta}$ \\
\hline T1 & 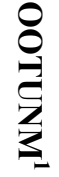 & $\stackrel{\sim}{A}$ & $\stackrel{N}{\infty}$ & $\begin{array}{l}\tilde{\sigma} \\
\stackrel{+}{\omega} \\
\sigma\end{array}$ & $\begin{array}{l}N \\
\infty \\
\dot{\infty} \\
\dot{\phi}\end{array}$ & $\begin{array}{l}0 \\
\dot{a}\end{array}$ & $\begin{array}{l}+ \\
\dot{\theta} \\
\dot{u}\end{array}$ \\
\hline T2 & $\overrightarrow{\mathrm{T}}$ & 蛋 & ஜ & $\begin{array}{l}\overrightarrow{8} \\
\stackrel{+}{\omega}\end{array}$ & $\begin{array}{l}\overrightarrow{0} \\
\dot{\omega} \\
u\end{array}$ & $\stackrel{\text { N }}{\text { N }}$ & $\dot{\omega}_{u}^{\dot{\omega}}$ \\
\hline T3 & $\sum_{w}^{Z}$ & $\begin{array}{l}\overrightarrow{0} \\
\underset{\omega}{\omega}\end{array}$ & $\frac{N}{a}$ & $\underset{\sim}{\infty}$ & $\begin{array}{l}\infty \\
. \\
w \\
w\end{array}$ & $\underset{\infty}{\vec{\infty}}$ & $\begin{array}{l}\underset{\tilde{N}}{u} \\
\stackrel{u}{u}\end{array}$ \\
\hline & \multicolumn{5}{|c|}{ Average Difference Level } & $\underset{\infty}{\overrightarrow{0}}$ & $\underset{\sim}{\stackrel{N}{J}}$ \\
\hline
\end{tabular}


Table 2. Validation in levels between Testing wells water level and Inverse Distance Weighted IDW Method.

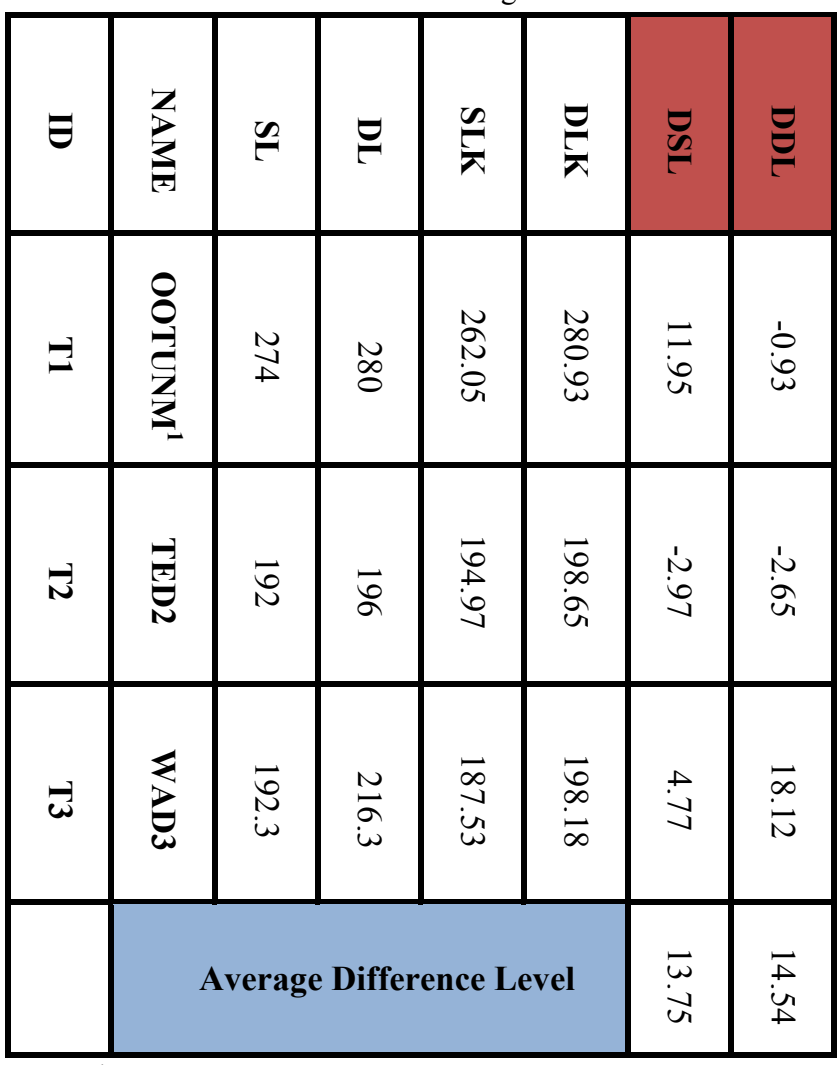

Where:

OOTUNM ${ }^{1}$ : Office of the United Nations Mission

TED $^{2}$ : The emergency department

WAD $^{3}$ : Wahid Athar district

\section{Conclusions}

Using different interpolation methods for prediction a static and dynamic water levels methods can give more options to indicate the more accurate one. The single interpolator cannot produce chief results for the generation of static and dynamic water levels maps, therefore we always using two-interpolation method. Four maps was produced, two for static water level in two methods ordinary kriging and IDW and they give some difference in spatial distribution of the static level due to the difference in equation and mechanism of each method. Furthermore, another two maps for dynamic water level as well same to previous two maps that produced by two different interpolation methods ordinary kriging and IDW with some difference in results of spatial distribution of dynamic water levels of wells. Generally, by using the validation technique for evaluation, all of the methods gave similar RMSE values. The method used in this study (kriging method) had better performance for $\mathrm{pH}$ in surface of soil also the lognormal kriging excellence both IDW and splines to interpolating electrical conductivity in surface soils. To identify most accurate interpolation method, three testing wells had used to validate which method is the best. The Emergency department well was the most accurate and nearest to the truth results of both static and dynamic water levels and even by using both ordinary kriging and IDW methods. However, IDW interpolation algorithm was the best, accurate and nearest than the ordinary kriging in overall average difference between testing and predicting stable and dynamic water levels of wells.

\section{Acknowledgment}

The author would like to express my thanks to the staff of the general commission for groundwater. Especially the Head of Department Dr. Ahmed Nazem, And I have to extend my sincere thanks to Eng- Fouad Mohammed sadiq . For his advice during my research. In addition, I have to extend my sincere thanks to Mr. Ali jassim nayyef and Mr. Sabah Ahmed Khorshid for their advice during work in my research.

\section{References}

1. Shiklomanov, Igor A. "World water resources." A new appraisal and assessment for the $21 \mathrm{st}$ century (1998).

2. Bear, Jacob. Hydraulics of groundwater. Courier Corporation, 2012.

3. Brander, Luke M., et al. Ecosystem Services 1.1 (2012): 62-69.

4. Çobanoğlu, İbrahim, Et Al. "Coğrafi Bilgi Sistemi (Cbs) Kullanilarak Adana İli Yerleşim Alaninin Hidrojeolojik Özellikleri $\mathrm{Ve} \mathrm{Su}$ Kalitesinin Değerlendirilmesi."

5. Çelik, Recep. Arabian Journal of Geosciences 8.6 (2015): 4279-4286.

6. Di, Minin Enrico, et al. "Global priorities for national carnivore conservation under land use change." (2016).

7. Ziary, Y., and H. Safari. Proceedings of FIG Working Week. Hong Kong 13 (2007). 